\title{
Infrastructures for collaboration in virtual organisations
}

\section{P.M. Wognum and E.C.C. Faber}

\author{
Department of Technology and Organisation, Faculty of Technology \\ and Management, University of Twente, PO Box 217, \\ 7500 AE Enschede, The Netherlands \\ Fax: +31 534892159 E-mail: P.M.Wognum@sms.utwente.nl
}

\begin{abstract}
Many organisations are currently forced to collaborate with others in renewing their products and processes to stay competitive, to enter new or to retain their current markets, or to get easy access to new knowledge. Management of collaboration between two or more organisations is, however, still not well understood, given that about half of the collaborative endeavours fail. A methodology to support management of collaboration is still lacking.
\end{abstract}

To build such a methodology, knowledge is needed on the process of collaboration. Much research has been devoted, however, to understanding the relationships between initial conditions and outcomes of a collaboration initiative. The results of this research are sometimes contradicting or not very well comparable because of differences in conceptualisation or ignorance of moderating factors. Moreover, a good design of initial conditions is necessary, but not sufficient. Conditions change during the process of collaboration. We need knowledge on the dynamics of the collaboration process to understand why and how conditions change and how they can be influenced.

In this paper an approach will be presented that can support the gradual building of knowledge on the process of collaboration. The approach, which resulted from the Esprit IV project 23286 FREE (Fast Reactive Extended Enterprise), can be viewed as a first step towards building a methodology to support management of collaboration. The concept of infrastructures for collaboration will be introduced stressing the integral nature of management of collaboration.

Keywords: Virtual organisation; organisational modelling; collaboration; communication.

Reference to this paper should be made as follows: Wognum, P.M. and Faber, E.C.C. (2002) 'Infrastructures for collaboration in virtual organisations', Int. J. Networking and Virtual Organisations, Vol. 1, No. 1, pp.32-54.

Biographical notes: P.M. (Nel) Wognum has been an assistant professor in the Department of Technology and Organisations of the Faculty of Technology and Management of the University of Twente in The Netherlands since 1996. She received a master degree in Computer Science in 1986 and a $\mathrm{PhD}$ in knowledge systems in 1990. She worked as an Assistant Professor in the Department of Computer Science from 1990 until 1996 in the Knowledge-Based Systems Group. Her main area of research is Concurrent Engineering in (networks of) industries with a focus on communication. She has participated in several European projects and networks.

Edward Faber obtained his bachelor's degree in Mechanical Engineering in 
1992. In the same year he started studying Technology and Society at the Eindhoven University of Technology. In 1995 he obtained his master degree in Technology and Society. From September 1995 to February 1997 he worked as a junior researcher at the Eindhoven University of Technology. In February 1997 he started working as a PhD researcher at the department of Technology and Organisation of the University of Twente. In 2001 he obtained his doctorate in Business Administration. His doctoral thesis is about managing collaborative new product development. Recently he joined the Telematics Institute, where he is working as a scientific researcher focusing on the organisational aspects of information and telecommunication technology.

\section{Introduction}

Companies are more and more forced to collaborate with others to maintain their competitive position and to react flexibly to changing demands. Partners may be selected based on strategic choices or based on more opportunistic reasons like the acquisition of technological knowledge. Sometimes, collaboration is enforced. For example, in the defence industry, collaboration is often enforced because of compensation orders, while in other industries, such as electronics, powerful parties may enforce adoption of standards (see e.g., [1]).

The development of new products and processes is an area in which collaboration between organisations is growing. Reasons for collaboration may be to spread the risk, to get easy access to new knowledge or to enter new markets. Moreover, to remain competitive, organisations have to decide what their core competencies are [2]. Manufacturers, for example, outsource the development of parts of their products to suppliers, requiring collaboration with the suppliers during the development process. Suppliers on the other hand are becoming responsible for complete subsystems of one or more of their clients' products in certain application areas (see e.g., [3]).

This paper will focus on organising and managing the development of new products and processes in temporary collaborative projects of two or more organisations. It will especially focus on the design and engineering phases of product and process development. The term collaborative engineering is currently used for denoting these phases in collaborative projects. The term virtual organisation is often used to denote the temporary collaboration between two or more organisations [4,5].

Not every collaborative endeavour is successful. Research has indicated that more than 50\% of them fail [6-8]. The reasons for failure are not yet well known. Much research has been devoted to studying the associative relationships between initial conditions and (perceived) success (see e.g., [9]). Results of this type of research are often contradictory. It seems that definition, underlying models and research approaches are not very well comparable.

Initial conditions are necessary conditions, but not sufficient conditions. The circumstances of a project often change, both externally and internally. These dynamics require decisions to be made:

1 on changes within the project, such as improving the team spirit or changing people's responsibility, or 
2 on changes in the mother organisation, like stopping or starting feasibility studies, replacing people, reducing or extending time and budget, arranging an additional review meeting, or changing the (communication) technology used.

Decisions on changes in the mother organisation have to be made in alignment with the partner organisations. For example, changes in the reporting procedure from project to mother organisation have to be aligned with the procedures in the partner organisations to prevent unnecessary conflicts. We need to build knowledge on the dynamics of a project to understand how initial conditions lead to a particular outcome. A process approach is needed to build such knowledge (see e.g., [10]).

To support the building of knowledge on the process of collaboration we introduce the concept of infrastructure for collaboration. An infrastructure is a roof concept. It concerns all basic facilities and services needed to support and manage collaboration, both organisational and technological. We will address the essential elements and relationships of the infrastructure to consider. We will present an infrastructure that is based on a model developed in the Esprit IV project 23286 FREE (Fast Reactive Extended Enterprise). We will also present the FREE methodology as a starting point for building knowledge on the process of collaboration. The FREE methodology provides an initial step in the development of methods, tools, and techniques for supporting management of collaboration.

The outline of this paper is as follows. In Section 2 we will operationalise the concept of collaboration in terms of communication and conditions that facilitate - and are shaped by - communication. These conditions are aspects of the infrastructure for supporting and managing communication, and, hence, collaboration. We will introduce the concept of communication infrastructure based on an organisational model that represents the essential elements and relationships of an organisation that are considered building blocks of the infrastructure. The infrastructure will be adapted to represent the essential elements and their relationships to consider in studying collaboration in virtual organisations. This adaptation is based on the FREE methodology, which will be presented briefly. The FREE methodology incorporates a process approach to management of collaboration. The dynamics of the process of collaboration require management to be a driving force in continuously adapting the infrastructure to changing circumstances. Performance measurement and capability assessment are essential elements of this approach. In Section 4 an example scenario will be presented of an improvement cycle. A brief discussion of the approach will be given in Section 5 . Finally, in Section 6 a brief summary of the paper will be presented.

\section{Collaboration in virtual enterprises}

Collaboration is a vague notion and requires more specific operationalisation. The operationalisation is based on a model that will be introduced below. The model is a refinement of a model developed in the FREE project mentioned above (for more information on the FREE project, see http://www.kcc.nl/free). The concepts underlying collaboration, namely communication infrastructure and communication behaviour, will be introduced in Section 2.1. We will discuss the concept of communication infrastructure in more depth in Section 2.2. We will adapt the concept for virtual organisations in Section 2.3. 


\subsection{A model of collaboration}

Collaboration requires coordination and communication between the partners in a virtual organisation. Coordination has been defined as managing dependencies [11]. A large range of mechanisms is available to achieve coordination [12,13] within or between organisational systems. Mintzberg [14] has identified three classes of coordination mechanisms, namely standardisation, direct supervision and mutual adjustment. Mechanisms from all three classes may co-exist in an organisation. Their configuration may vary for different organisational subsystems and on different levels in the organisation. The choice for coordination mechanisms depends on the degree of uncertainty and newness involved in the tasks to be performed (see e.g., [15]).

In the order mentioned, the importance and necessity of communication for achieving the required level of coordination increases. Communication, in turn, very much depends on the degree and nature of coordination within or between organisational systems. Paraphrasing Giddens [16], coordination is both the medium and outcome of communication (see also [17]).

The way the communication process proceeds, especially informal communication, is often viewed as an indication of the degree of collaboration (see e.g., [18]). On the other hand, the actual process of formal communication may also indicate how well partners are working together. Large gaps between expected formal communication behaviour and actual behaviour of the partners involved may indicate an insufficient degree of collaboration, requiring changes in the organisational systems involved.

Figure 1 Operationalisation of collaboration

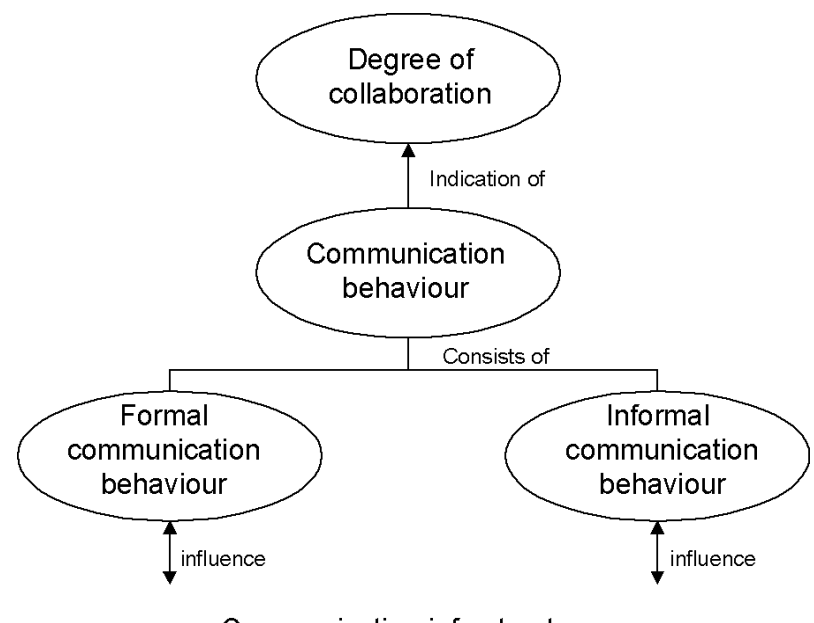

Communication infrastructure

In the model depicted in Figure 1, the degree of collaboration is indicated by communication behaviour that consists of formal and informal communication behaviour. Both types of communication behaviour are influenced by the communication infrastructure needed to facilitate and manage communication. In turn, both formal and informal communication influence the communication infrastructure. This infrastructure 
comprises the basic facilities and services needed to support and manage communication. This concept will be discussed in more detail in Section 2.2. Following Giddens [16] communication infrastructure is thus both the medium and outcome of communication behaviour. In addition, communication infrastructure can be viewed as the institutionalisation behind and the outcome of the design mode of communication behaviour, while the use mode is represented by the way the communication process is actually performed (cf. [19]).

\subsection{Communication infrastructure of an organisation}

An infrastructure comprises 'the parts of a system that compose the whole' according to the Oxford dictionary [20]. The concept of infrastructure is rather old and denotes a large variety of structures to support and manage flows such as the road network and all accompanying facilities and services. In the context of information systems, the concept of infrastructure has been used mainly in a technical sense, denoting networks, computers, software and additional necessary devices.

By contrast, Truijens et al. [21] define the concept of infrastructure in a wider sense to denote all basis facilities necessary to secure the development of information systems and the control of these processes. This concept of infrastructure includes several more specific infrastructures: data infrastructure, system infrastructure, communication infrastructure (technical), configuration infrastructure and organisation infrastructure. These lower-level infrastructures cover the essential organisational and technological elements and relations between them that need to be taken into account in organising, monitoring and improving the process of information system development.

We will define the concept of communication infrastructure in a similar way. We will formulate the concept of communication infrastructure in terms of variables of the Process-based contingency Model of Organisation (PMO) [22-25]. According to the $\mathrm{PMO}$, an organisation should be internally and externally consistent to be effective and efficient [22,26]. Using specific operationalisations (instantiations) of the PMO, inconsistencies in organisational systems can be determined, such as inconsistencies in production systems [27,23] and inconsistencies in product development systems [22]. Based on the analysis, ideas for improvement can be defined and implemented, while taking into account the specific relationships between organisational variables $[23,28]$. The fewer inconsistencies can be found the better the alignment (or fit) between the organisational variables under study.

According to the PMO, an organisation is viewed as a goal-oriented system consisting of people and means which together perform the processes in the organisation. The system consists in essence of a goal and strategy that has to be aligned with needs in its environment, people and means that perform processes to achieve the goal, and organisational arrangements that divide and coordinate the work in an organisation. The PMO can be considered as a metamodel, or ontology of an organisational system. To apply the PMO to study or analyse specific systems, additional theories and models are needed that explain or represent characteristics of these systems, like theories on organisational structure or behaviour, marketing models, personnel management, etc. For example, to study project management in an organisation, literature on organising and managing projects or literature on leadership styles may be used to specialise the PMO for this purpose. In the same vein, literature on knowledge management may be used 
to study the possibilities for reusing information and knowledge in future projects (see e.g., [29]).

Figure 2 Communication infrastructure for supporting and managing communication in an organisation

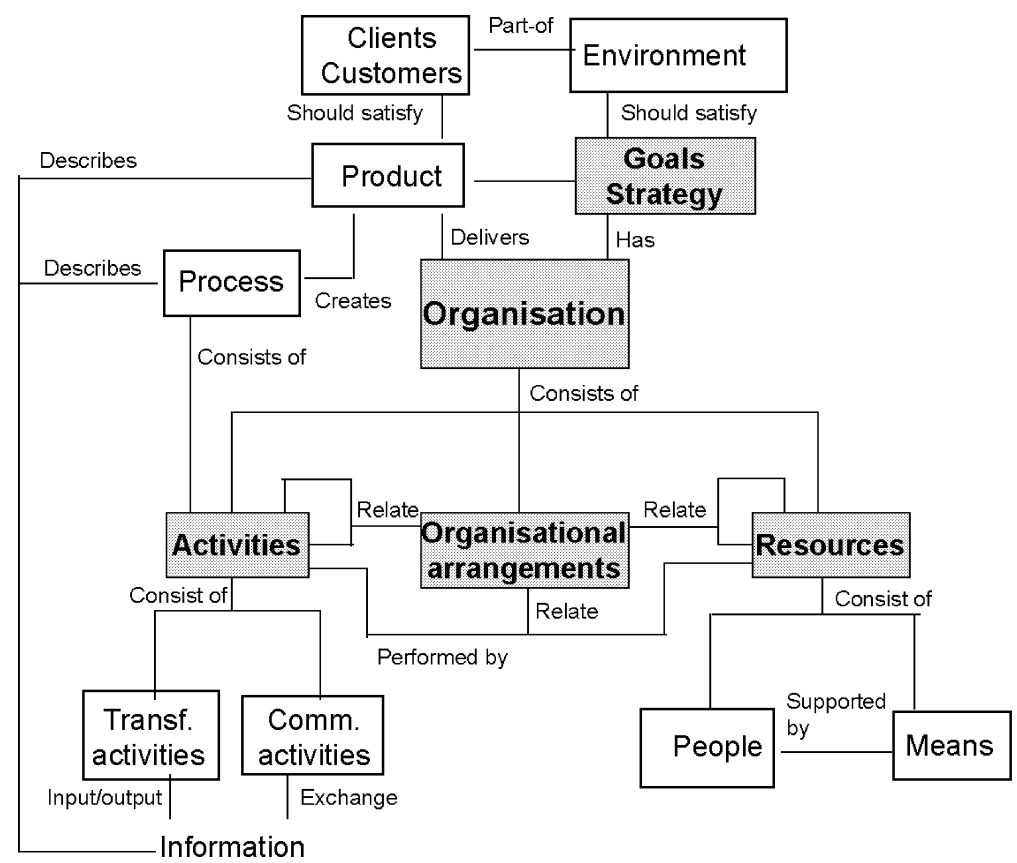

Below, we will specialise the variables of the PMO for a communication infrastructure. We restrict this specialisation to product development systems. The variables and relationships are depicted in Figure 2. The variables are the following:

- Environment consists of the external environment of an organisation. The external environment consists of clients, customers, competitors, government, legislation, financial institutes, etc. This environment can be extended with a task environment for subsystems of the organisation, such as the product development system or the production system. The task environment consists of all other subsystems in the organisation, which influence or are influenced by the subsystem under observation. Characteristics of the environment, like uncertainty, dynamics, or hostility determine information needs. The communication infrastructure should satisfy those needs, e.g., in terms of information processing capacity and capability (see e.g., [30]) by choosing a suitable organisational structure (see below) including an appropriate set of coordination mechanisms. In addition, the degree of involvement of suppliers in the task environment also determines the information needs, e.g., early supplier involvement or full system supply (see e.g., [3]).

- Clients/customers: the set of clients/customers of (potential) interest in the general environment of an organisation. The dynamics, size, variety of this set influences the 
degree of communication with the environment needed to acquire or maintain market information.

- Strategy and goals of the organisation as well as strategy and goals of subsystems, like the product development subsystem. Strategy and goals of a subsystem should be aligned with the organisational strategy and goals. In turn, strategy and goals of the organisation should be aligned with the (relevant) needs in the environment. The success of an organisation depends on how well it satisfies certain needs in its environment. Communication with (elements in) the environment is necessary to determine which goals to set at what time. Moreover, communication within the organisation, between subsystems and organisational levels is needed to achieve shared goals and strategy. Shared goals and strategy in turn help to focus communication or may improve communication behaviour.

- Product: characteristics of the product in terms of newness or complexity determine the amount of information that needs to be exchanged between people involved, like engineers, managers, and clients/customers.

- Processes comprise management processes (strategic, adaptive, and operational), primary processes, support processes, learning processes and communication processes. Strategic management defines high-level goals and strategy, as well as the processes and technologies to be used. Adaptive management chooses the configuration of processes, resources, organisational arrangements suited to achieve the strategic goals. Operational management controls the primary process within the limits set. For example, operational management sets deadlines for document delivery and monitors activities for timely delivery or reducing time losses. Support processes provide the other processes with sufficient and sufficiently qualified people and means. Primary processes are directly aimed at satisfying the goals by delivering products that are wanted by (future) clients/customers. Processes consist of activities. Besides communication activities, all activities transform input information into output information. Communication activities exchange information between transformation activities. Each transformation activity requires and delivers specific information. The degree of complexity and uncertainty of the product and process to be developed defines the required quality of information (timeliness, relevance, reliability), the required quality and quantity of people and means, the communication activities needed and the particular organisational arrangements needed to coordinate all this. Information and knowledge management as well as education of people in using communication means are (part of) support processes.

- Information may consist of product information (including the process to be developed) as well as process information for monitoring purposes. Information can be characterised by several aspects: its content (e.g., technical, procedural, managerial, social), its function, its quality (timeliness, relevance, reliability) (see e.g., [31]), its form and location; these aspects have an impact on the other elements of the communication infrastructure, like the communication means, communication activities, organisational arrangements and the characteristics of the people involved in communication. 
- $\quad$ People perform processes with the help of means. People are essential in communication; their capabilities, such as knowledge, skills, experience, attitude, and commitment strongly influence communication behaviour.

- $\quad$ Means are e.g., methods, techniques, tools, machines, knowledge. Sometimes, means can perform steps in a process. Means facilitate communication to a large extent. Communication behaviour depends on the appropriateness of communication means in a particular context.

- Organisational arrangements are the more or less durable means to assign and coordinate the work in an organisation. Organisational arrangements provide the relationships between people, means, and processes. They can be formal as well as informal. Together they constitute the structure as well as the culture of an organisation. Organisational arrangements apply to multiple levels: individual, group, subsystem and organisation. Organisational arrangements, like procedures, meeting structure, team structure, physical and technical infrastructure, working environment and social environment are expected to have a strong impact on communication behaviour.

Patterns of instantiation of organisational systems are known as organisational structures. Well-known dimensions of organisational structure are configuration, complexity, formalisation, and centralisation (see [32]). These dimensions have been used in research relating organisational structure and communication. However, this research has not yet led to consistent results. Moreover, longitudinal research, needed to understand the relationships between structure and communication behaviour, is rather limited [32]. To support longitudinal research on the evolution of communication and, thus, collaboration, the communication infrastructure introduced above will provide (classes of) the essential organisational and technological elements and relationships to consider.

The communication infrastructure as depicted in Figure 2 represents an integral set of facilities and services to support and manage communication. Communication activities are part of the infrastructure as far as they are explicitly defined and organised. These activities are, hence, mainly restricted to formal communication activities.

Communication behaviour depends on the communication infrastructure and can only be observed in real practice. Communication behaviour consists of formal communication behaviour and informal communication behaviour, as has been defined above (see Figure 1). Informal communication behaviour also depends on the communication infrastructure, but consists of communication activities autonomously started and executed by the people involved. Communication behaviour in turn may lead to changes in the communication infrastructure (see also Figure 1), spontaneously as well as by management intervention, desired as well as undesired.

The communication infrastructure defines desired as well as expected communication behaviour. Desired behaviour is expressed in e.g., project plans with respect to review meetings and document structure. Expected behaviour may divert from desired behaviour due to factors like trust between and flexibility of the people and disciplines involved and the amount of shared knowledge [33]. Communication behaviour may divert from desired or expected behaviour. Decisions on improvements to the communication infrastructure depend on analysis of the gaps between desired/expected behaviour and actual behaviour. 
In the context of a virtual organisation the communication infrastructure as defined above is also applicable. However, communication in virtual organisations is complicated by the distance in time, space, culture, working procedures and organisational structures between the people involved. As Allen [34] has shown communication tends to decrease with increasing distance. Our experience is that this is still true despite the availability of electronic communication means such as e-mail. Below, we will discuss the concept of communication infrastructure of a virtual organisation in more detail.

\subsection{Communication infrastructure of a virtual organisation}

To explain the differences between a 'normal' organisation and a virtual organisation, the communication infrastructure has been adapted to incorporate the essential elements of a virtual organisation. In Figure 3, (a part of) the communication infrastructure for a virtual organisation has been depicted. The essential difference between a 'normal' organisation and a virtual organisation is that a virtual organisation consists of two or more partners who are themselves part of a mother organisation. Differences between a virtual organisation and a mother organisation as well as differences between the partners involved influence communication behaviour.

Figure 3 Communication infrastructure to support and manage communication in a virtual organisation

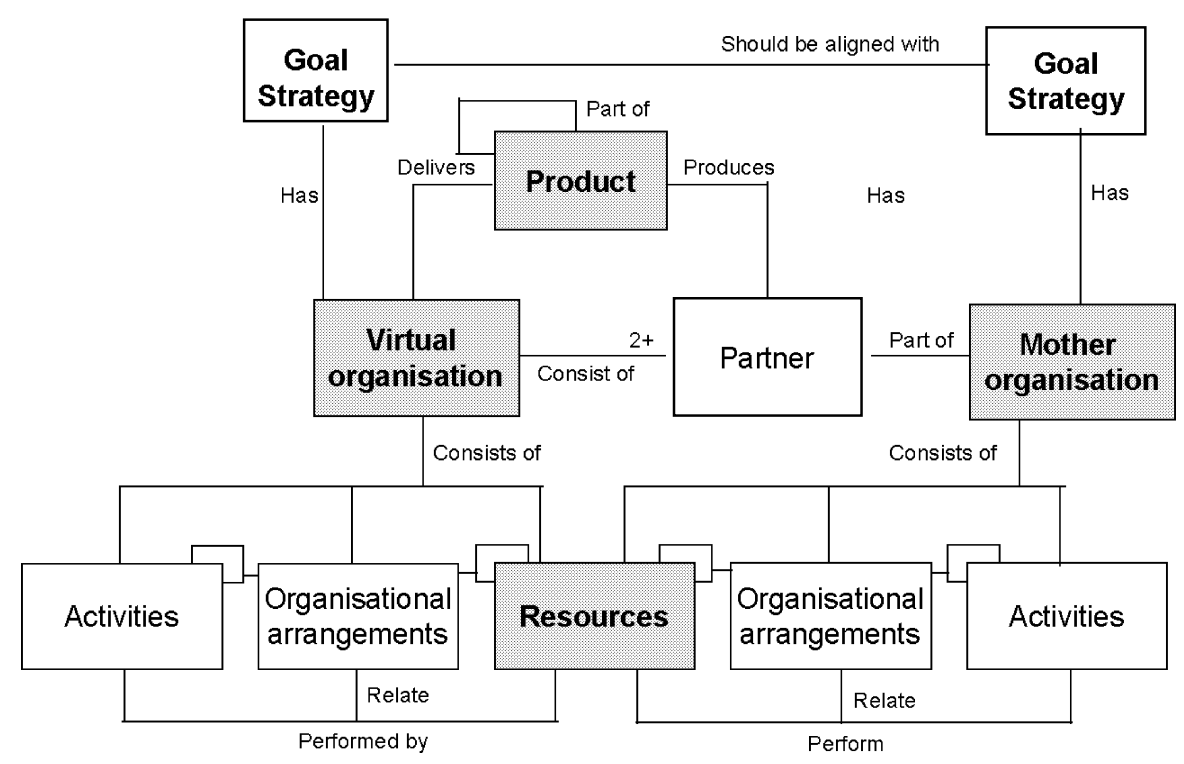

The virtual organisation is an organisation with its own goals and strategy for which specific activities and organisational arrangements have been defined. The activities are mainly management, support and communication activities. The primary activities are mainly performed in a mother organisation. A mother organisation has goals and a strategy that should be aligned with the goals and strategy of the virtual organisation. Large differences between the goals of the mother organisation and the virtual 
organisation may negatively influence communication e.g., because of limited commitment towards these goals of the people involved. Below, we will describe some essential areas of differences that may have an impact on communication.

- The environments (not in the figure) of the mother organisations involved may overlap. For example, in some industries competitors are forced to collaborate (temporarily) in a virtual organisation. Such a situation may hamper communication. The transfer of knowledge, e.g., between the people involved may be restricted for national or legal reasons leading to insufficient sharing of the knowledge needed for performing the primary activities.

- The resources of a virtual organisation have been assigned by the respective mother organisations to the part(s) that participate(s) in the virtual organisation. Alignment of competencies of people from different organisations is essential as well as interoperability of the means (not only technical) involved. The people involved in a virtual organisation have to adapt to the context of the virtual organisation in terms of the infrastructure defined for the virtual organisation, but they will bring working habits and social rules from their mother organisation. Moreover, a large part of the activities is still performed in the context of the mother organisation, possibly tipping the scale towards a larger influence of the mother organisation. Large differences between partners, in terms of people, means, organisational arrangements, culture, and goals may negatively influence communication especially when these differences are not recognised.

- The product delivered by the virtual organisation to clients/customers (not in the figure) consists of subsystems/parts that are produced by the partners. This situation poses specific quality demands on product and process information (not in the figure) delivered by the partners. For example, differences in terminology and interpretation frameworks may disturb communication. In addition, when not sufficiently defined in the virtual organisation beforehand, differences in (documentation) standards and information management facilities may lead to misunderstandings, conflicts and delays.

From this discussion it will be clear that communication infrastructure of a virtual organisation is a multi-dimensional, multi-level concept. It is multi-dimensional, since it involves several different aspects, such as process aspects, people aspects, technological aspects, and organisational aspects. It is multi-level, since it can be specified on the individual level, the group level, the project level, and the organisational level. Moreover, as already indicated above, designing a communication infrastructure cannot be a oneshot approach, because people are part of the system with their own goals, preferences, and expectations. Instead of a system with fully programmed behaviour we will have a system that performs in unexpected ways, sometimes different but acceptable, sometimes undesired, requiring changes to the communication infrastructure. Moreover, circumstances may change, also requiring adaptations to the communication infrastructure. A process approach to managing collaboration is needed to deal with these dynamics.

To support management of collaboration, methods, tools and techniques are needed, which are currently lacking. Building the required support requires extensive knowledge of how the process of collaboration evolves. The knowledge has to be built in an evolutionary fashion together with building the methodology to support management of 
collaboration. In the next section, we will briefly discuss some aspects of the knowledge building process. After that, in Section 3, we will present an approach that can be considered as a first step towards a methodology to support management of collaboration and to building knowledge on the collaboration process.

\subsection{Knowledge building}

Building knowledge on the evolution of collaboration in a temporary collaboration project or virtual organisation requires a longitudinal approach and study of many different projects. On the one hand, organisations should designate resources to enable knowledge building. On the other hand research institutes should systematically gather and exchange study results to enable theory building and the development of suitable tools, methods and techniques.

Knowledge building in organisations requires a knowledge management approach. This means that the organisational system as described above should enable the systematic and continuous maintenance, update, and use of knowledge on collaboration. Knowledge management can be implemented in many different ways depending on the type of knowledge involved and the structure and culture of the organisation [35]. As can be expected, knowledge on collaboration projects will be explicit and implicit, technical as well as social, and can be stored in people's heads, in documents and technical infrastructure. The knowledge management approach needed to build and use the required knowledge base will therefore consist of a collection of technological and organisational solutions. Current endeavours to develop solutions to solving part of the collaboration problem (see e.g., [36]) will provide part solutions for knowledge management.

In the international research community the importance and complexity of collaboration between different organisations as well as the importance of developing theories, methods, tools and techniques to support (management of) collaboration has been recognised. In the ESPRIT 4th Framework and the 5th Framework program IST of the European Community, especially Key Action II [37] many projects have been defined that deal with one or more aspects of collaboration in virtual organisations. The participation of industries is required to achieve useful results. Conferences are organised to enable exchange and integration of research results and alignment of terminology and models, such as the International Conference on Concurrent Enterprising (ICE) [38,39] and Infrastructures for Virtual Enterprises (PRO-VE) [36]. In addition, integrating projects are needed to provide the knowledge management necessary to develop widely accepted theories and methods, tools and techniques.

\section{Improving collaboration}

To support management of collaboration we have adopted the well-known ShewhartDeming quality cycle [40] in the FREE project. This cycle, developed in the context of quality management, stresses the iterative nature of monitoring and improvement activities. This approach is also suited to monitor and improve communication behaviour, both formal and informal.

The quality cycle (see Figure 4) consists of the following steps: 
- Plan: this step consists of a thorough analysis of problems encountered, either by people in the organisation or by the application of a performance measurement system: based on the analysis an improvement goal and an improvement plan are defined;

- Do: this step consists of the execution of the improvement plan: improvements to the communication infrastructure are implemented;

- Check: this step consists of observation and measurement of communication behaviour to determine to what extent improvements have been successful: when measurements conform to expectations, the do phase continues unless finished;

- Act: this step leads to decisions to:

1 accept differences between actual behaviour and desired/expected behaviour leading to continuation of the do phase or acceptance of the improvements, or

2 reject differences leading to adaptation in the improvement plan, thus starting a new improvement cycle.

Figure 4 Improvement cycle

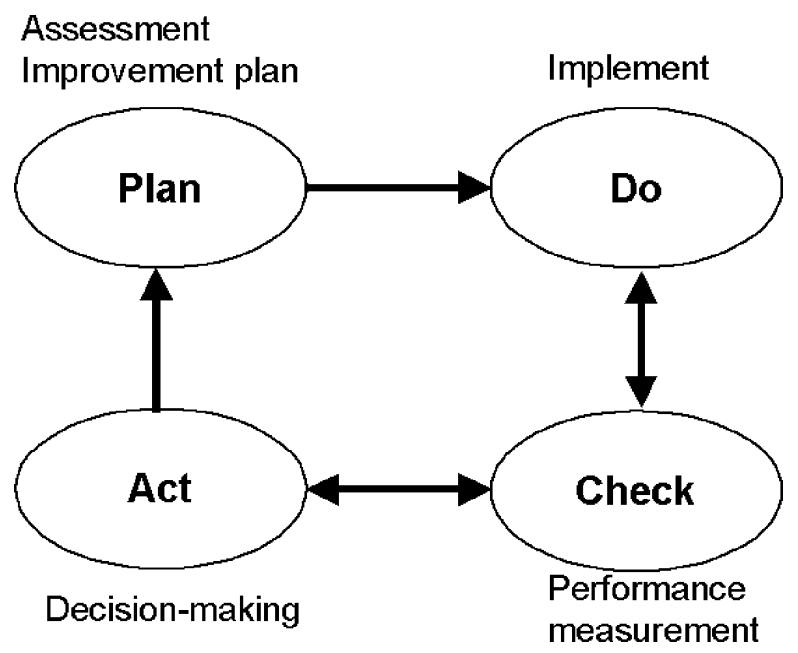

In the FREE project the improvement cycle has been implemented in the FREE Improvement Framework (FREE-IF [41]), which is one of the products of the FREE project. The FREE-IF provides a starting point for improving the quality of operation of a virtual enterprise, with a focus on collaboration. It provides a default scenario that has to be adapted to specific types of a virtual enterprise. The FREE-IF is a framework in which the other FREE products have been integrated. These products are:

1 A generic organisational model (FREE organisational model [42]), in which potential problem areas with respect to collaboration in a virtual enterprise are represented. The model is built from key elements and relationships that allow managerial intervention. The purpose of the model is to describe an existing virtual organisation and to provide a scoping mechanism for problems that have been 
detected, which means that the model supports selection of the relevant part(s) of a virtual enterprise that need(s) to be improved. The FREE Organisational model is based on the PMO and adapted to a generic representation of a virtual organisation. In Figure 3 a restricted version of the model is depicted. The communication infrastructure defined above builds on the FREE Organisational model.

2 A Capability Assessment Framework (FREE-CAF [43-45]) that supports assessment of current practices in a virtual enterprise and selection of applicable key practices at several maturity levels both in a virtual enterprise and in partner organisations. Assessment of partner organisations is aimed at identifying their capability to participate in a virtual enterprise. The FREE-CAF provides support in deciding on what to change in the selected part of the virtual enterprise. It is based as far as possible on the CMM theory, structure and terminology developed by SEI-CMU (see e.g., [46]). The FREE-CAF contains an extensive library of key practices for a virtual enterprise and its partners.

3 A Performance Measurement Method (FREE-PMM [47,48]) that supports measuring the performance of (collaboration in) a virtual enterprise in operation. The method applies both to the performance of an improvement project and to the daily operation of a virtual enterprise. The FREE-PMM addresses the most important issues concerning the definition and use of a performance measurement method. It consists of a methodology to develop a performance measurement method for a specific virtual enterprise as well as practical examples of the use of such a method and a list of potential performance indicators.

4 A specific version of the FREE deliverables for SMEs has been developed [49,50]. The SME adaptation contains simplified versions of the FREE-CAF, the FREEPMM, and the FREE-IF based on concrete experiences. The FREE organisational model has played an important role in structuring the capabilities for SMEs.

In addition to the products described above, a navigation tool has been developed that provides an initial idea on how to use the products [51]. The navigation starts with the definition of a business issue, which means a specific improvement goal to be achieved. The management of the collaboration to be improved may have formulated this business issue based on systematic performance measurement or dissatisfaction with the current situation (for an example, see next section). Next, the business issue is related to FREE model elements that may require improvement. Management will make this selection. Systematic support for this selection is a topic of future research. The model element selected will be related to one or more Key Process Areas from the FREE-CAF. Capability assessment may support and extend this selection. After selection of the Key Process Areas, an improvement plan has to be defined after which the improvement cycle starts.

The deliverables of the FREE project are based on extensive knowledge of the FREE project partners on projects performed in partnership and on the literature on virtual enterprises. The deliverables have been validated by peer reviews. The deliverables have to be further evaluated and refined by applying them in practice. This will be part of follow-up projects.

The FREE-CAF and the FREE-PMM are especially relevant for this paper. The FREE-PMM has been a first identification of existent performance measurement methods 
that can be used in the context of monitoring the quality of operation of a virtual organisation, with a focus on communication. The FREE-CAF is a first attempt to combining existing capability maturity models and adapting them for use in a virtual organisation including the partner organisations involved. We will discuss both products briefly below.

\section{$3.1 \quad$ Performance measurement}

For monitoring communication behaviour, the FREE-PMM provides a useful starting point. It identifies possible focus areas and related performance indicators. Moreover, it stresses the definition of a goal to be achieved to enable evaluation of observed and measured performance. The FREE-PMM can be used to measure actual process performance. More specifically, it is focused on measuring alignment between partners in a virtual organisation and the performance of the communication process (see Section 2.1). It is also related to the FREE-CAF, since goals to be achieved can be realised through implementation of specific Key Process Areas. Performance Indicators have been defined for each KPA to measure the success of its implementation.

The FREE-PMM provides a method that has to be specialised for each specific virtual organisation. Each virtual organisation is to some extent unique. This means that the performance measurement method and selected performance indicators used in one virtual organisation cannot be used as such in another. However, the question rises whether generic performance measurement methods can be developed for classes of virtual organisations. In the context of product development systems in organisations this appear to be a question that is as yet difficult to answer. Characteristics of product development systems found in the literature (e.g., complexity, newness, market orientation) lead to overlapping classes [52]. It can be expected that this will also be the case for virtual organisations with product development tasks. Further research is needed to identify guidelines for specifying performance measurement goals, methods and indicators for monitoring communication in (classes of) virtual organisations. The FREEPMM $[47,48]$ will provide a useful starting point for this purpose.

In $[47,48]$ examples of potential performance indicators can be found. These indicators are related to business issues. For example, for the business issue 'improve interfaces between a virtual enterprise and parent organisations' the following performance indicators have been suggested, amongst others: level of effective facilities management, use of tools, quality management, team training, priority alignment.

\subsection{Capability assessment}

The FREE-CAF is a comprehensive framework that is based on several existing capability maturity models and assessment methods (for an overview, see [45]). The starting point of the FREE-CAF is the Capability Maturity Model (CMM) developed by the Software Engineering Institute (SEI) of CMU [46]. The FREE-CAF provides a collection of best practices, ordered according to maturity levels, that, when adapted for use in a specific virtual organisation, support management of collaboration to the extent covered by a maturity level. A maturity level specifies which capabilities an organisation should have to enable behaviour as specified for that level. The maturity levels are listed in Table 1 below. The FREE-CAF also provides performance indicators to monitor the 
implementation of the best practices. This last facility of the FREE-CAF complements the FREE-PMM.

The best practices formulated in the FREE-CAF (Key Process Areas - KPAs) are applicable to a virtual organisation, a partner organisation, or both. In the following table we list the currently available KPAs. The list starts with maturity level 2, where processes have been defined and support activities have been implemented. The KPAs have also been ordered according to aspects of the FREE organisational model. These aspects, called process subdomains in the FREE-CAF are the following [45]:

- Environment: this subdomain indicates relationships of a virtual organisation with its environment, consisting of e.g., mother organisations, customers, social environment and other stakeholders. This is the external perception of the behaviour of a virtual organisation in terms of the quality of operation.

- Organisation of a virtual organisation, which facilitates and regulates the quality of operation.

- Shared processes, which focus on the integration, collaboration and communication in a virtual organisation.

- $\quad$ Resources: resource management of a virtual organisation includes workforce management, assets management, knowledge management and financial management.

Through this structuring of KPAs problem areas identified in a virtual organisation with respect to the quality of operation can be related to relevant KPAs through FREE organisational model elements, as illustrated in the navigation tool.

Table 1 Key process areas ordered according to organisational dimension and maturity level

\begin{tabular}{|c|c|c|c|c|}
\hline $\begin{array}{c}\text { Maturity } \\
\text { level }\end{array}$ & Environment & Organisation & Shared processes & Resources \\
\hline \multirow[t]{2}{*}{$\begin{array}{l}\text { Level } 5 \\
\text { Optimising }\end{array}$} & $\begin{array}{l}\text { Knowledge transfer } \\
\text { management }\end{array}$ & \multicolumn{3}{|c|}{ Continuous improvement and innovation } \\
\hline & Partnership learning & \multicolumn{3}{|c|}{$\begin{array}{l}\text { Shared process improvement, including technology and } \\
\text { business environment change management }\end{array}$} \\
\hline \multirow[t]{2}{*}{$\begin{array}{l}\text { Level } 4 \\
\text { Managed }\end{array}$} & Public responsibility & Team monitoring & $\begin{array}{l}\text { Shared process } \\
\text { improvement }\end{array}$ & $\begin{array}{l}\text { Competency } \\
\text { management }\end{array}$ \\
\hline & Result orientation & $\begin{array}{l}\text { Collaboration } \\
\text { facilitation }\end{array}$ & & \\
\hline \multirow[t]{4}{*}{$\begin{array}{l}\text { Level } 3 \\
\text { Defined }\end{array}$} & Alliance enhancement & $\begin{array}{l}\text { Interoperability } \\
\text { enforcement }\end{array}$ & $\begin{array}{l}\text { Shared process } \\
\text { definition }\end{array}$ & $\begin{array}{l}\text { Workforce } \\
\text { competency } \\
\text { management }\end{array}$ \\
\hline & & $\begin{array}{l}\text { Communication } \\
\text { enablers }\end{array}$ & & People rewarding \\
\hline & & & & $\begin{array}{l}\text { Collaborative } \\
\text { information } \\
\text { infrastructure }\end{array}$ \\
\hline & & & & $\begin{array}{l}\text { Assets } \\
\text { management }\end{array}$ \\
\hline
\end{tabular}

Level 2 Customer focus $\quad$ Enterprise $\quad$ Program $\quad$ Workforce




\begin{tabular}{lllll}
\hline Repeatable & & integration & operation & adaptation \\
& & management & \\
& Leadership and & Team initiation & $\begin{array}{l}\text { Program } \\
\text { consistency of purpose }\end{array}$ & \\
& & $\begin{array}{l}\text { initiation } \\
\text { management }\end{array}$ & \\
\hline
\end{tabular}

For example, the model element 'product' points to KPA 'Customer focus' amongst others. This KPA deals with the development of a customer focus behaviour of the workforce in the virtual organisation. As one of the commitments formulated in the KPA, an organisational role has been assigned responsibility to develop the customer satisfaction strategy and implementation plan. This role will contribute to developing the capability to design and produce a product that satisfies the customer.

The FREE-CAF provides a suitable starting point for defining a communication infrastructure for specific virtual organisations taking into account the current maturity level and desired improvement scenarios. The FREE-CAF is not a normative framework in the sense that it forces organisations to adopt the KPAs as such. Instead, each virtual organisation and its partners should select and adapt KPAs for their own situation. The FREE-IF as well as the guidelines formulated in the FREE-CAF may provide support for this task. However, as already indicated above, further research is needed to identify possibilities to define guidelines for instantiating best practices for specific types of virtual organisations. Moreover, in the current best practices as defined in the FREECAF, work-related practices and maturity-related practices are mixed, as in CMM. Separating the work-related practices (base practices) from the maturity-related practices (generic practices) as in Systems Engineering CMM (SE-CMM [53]) may be the next step to perform.

\section{Example of an improvement scenario}

Below we will sketch a scenario to illustrate the use of the FREE products. It shows the navigation through the products in defining an improvement plan. We will apply the scenario to a problem in communication behaviour of the virtual organisation under study. The following steps can be performed to define an improvement plan (a more thorough walkthrough can be found in the FREE-IF [41]:

Step 1: Specify the collaboration problem that has to be solved. This problem may have been identified by means of the FREE-PMM or by people in the virtual enterprise who are dissatisfied with the current behaviour.

For example, it has been observed that documents to be reviewed in a collaborative product development project are always too late. This problem will contribute to missing deadlines, which may lead to increased costs.

Step 2: Define the process that contains the problem. This process will be called the focus process. The focus process will most often be a transformation process, e.g., a management process, a (particular phase in the) primary process, or a support process. 
For example, for our situation the primary process is the focus process. Because we do not want to improve the primary process itself (people knowledge and skills are considered sufficient), the focus process is the communication process in the primary process. More specifically, the phase of interest in the primary process is the detail-engineering phase in the product development process.

Step 3: Define the desired situation that will solve the problem. The desired situation can be considered as the business issue for an improvement initiative.

For example, from a list of business issues we may choose one that suits us. We choose 'Reduction of product development duration'. This business issue consists of a list of lower-level business issues (see Table 2). Each business issue may be further refined (not shown). For example, resources availability can be refined into the availability of people and means, while the issue on interfaces can be refined to incorporate the different types of organisational arrangements. We will choose the business issue 'Improved interfaces', because we have observed that on this point some improvements may be necessary. More specifically, people involved in the detail engineering phase do not (re)act as expected, e.g., choices, necessary for others in the process, are not made or made too late, while people expected to participate in the process do not show up. Improved interfaces may concern mutual understanding between people, interoperability between technology, alignment between organisational arrangements, etc.

Table 2 Business issues on reduction of product development duration

Reduction of product development duration

Alignment of strategy and goals

Enhanced reusability of product parts

Improved project control

Improved resource availability

Improved interfaces between a virtual enterprise and mother organisation

Step 4: Identify, which part of the organisation must be improved. To support this task, business issues have been related to model elements that represent the organisational parts that may be addressed. Select the model element(s) that are most relevant for the situation encountered.

For example, from the issue 'Improved interfaces' we choose 'Process and activity structure' from the model elements, since we have the impression that tuning of activities between partners could be improved to improve communication. For example, if in one mother organisation activities are structured in a sequential fashion with explicit milestones in between, while in another mother organisation people are used to starting activities from a next phase before milestones have officially passed, communication problems may occur. In one organisation, people may wait for official approval to start new activities, while in the other organisation, people cannot start because information on the new activities is not forthcoming. Moreover, the priorities of the collaboration tasks may be different for the organisations involved, leading to people giving priority to their functional tasks. 
Step 5: Select possibly relevant Key Process Areas (KPAs) by traversing the links from model elements to KPAs. KPAs are a means to achieve the necessary alignment between partners and the virtual organisation and within the virtual organisation (see Figure 1). The goals stated for each KPA [45] may support the selection task.

For example, from the list of KPAs that relate to 'Process and activity structure' we choose 'Shared process definition' and 'Collaborative information infrastructure'. The first KPA deals with the development, implementation, and maintenance of interoperable processes. The second one addresses the sharing of policies, methods and procedures between partners. From this point on we can follow the guidelines of the FREE-CAF. For example, implementation of the first KPA requires that:

1 the virtual organisation follows a documented policy for its shared process definition,

2 process management activities of mother organisations are committed to support the virtual organisation shared process definition activities, and

3 an organisational role is assigned responsibility to co-ordinate the development of the virtual organisation standard shared processes.

Several capabilities have been defined that have to be realised in the desiredsituation.

Step 6: Define improvement actions. The FREE-IF [41] will support this task. The FREE-CAF supports definition of the desired situation. The definition of improvement actions, however, still depends heavily on knowledge available in the different mother organisations.

Step 7: Select appropriate performance indicators to be able to check the performance of improvements from the selected KPAs. In addition, by traversing the links from business issues to the FREE-PMM [47,48], additional performance indicators may be found that can be used to observe improvements in communication behaviour.

For example, the same indicator 'timely delivery of documents' can be used to observe overall improvements.

The necessarily limited steps shown above can support a business analyst in identification, analysis, and definition of improvements with respect to the quality of operation of collaboration in a virtual organisation. Our approach does not yet support the implementation process, but can be used to plan and monitor the effectiveness of the improvement. It does not prescribe a solution but supports people in selecting a solution. In our view, people in an organisation often have an idea of the problem at hand, but need support in finding its causes and corresponding solutions. The solutions we provide through the model elements and the KPAs are sufficiently generic to be applicable to a large set of problem areas in inter-organisational product development. On the other hand, they are expected to help people to define improvement initiatives that are specific for the situation at hand. 


\section{Discussion}

As identified above, there is not yet a generic classification of types of product development. Such a classification is expected to be even more complex for clustering types of product development in virtual organisations or temporary collaborations. For example, the degree of involvement of partners may vary. In current buyer-supplier relationships, e.g., product development may be performed by the buyer with early supplier involvement, by the supplier according to requirements formulated by the buyer, or in a shared fashion (see e.g., [3]). Different configurations of partners in the product development process may lead to different communication needs. We do not fully understand yet the communication needs of these different situations. Communication needs, in turn, have to be translated into a suitable communication infrastructure to support and manage communication. Guidelines to defining a suitable communication infrastructure are still lacking.

Current monitoring and improvement of collaboration in virtual organisations is performed in a rather ad hoc way. Standards to support decisions to improve communication are only available for aspects of the communication infrastructure. One example of such standards concerns process models, like the VDI model, as a standard reference model for structuring the design process [54]. Similar models can be found in software development methods, such as the DoD and IEEE standards (see e.g., [55]) and project management methods (see e.g., [56]). These models are aimed at improving the planning and control of the design process. Instantiation of the model depends on the characteristics of the collaborative product development project. However, differences in types of projects are not generally recognised (see e.g., [25]).

Other examples of standards can be found at the level of the product and process design activities. STEP, for example, provides a product modelling standard and exchange format. The applicability of formats like STEP depends on the efforts partners must make to adopt and implement this standard. Process modelling standards like IDEF0 help to optimise the process activity structure. However, optimising the process activity structure has to be balanced against the organisational changes needed to effectuate the optimisation.

In addition to existing product and process modelling standards we need standards at the organisational level as reference models for selecting and implementing infrastructures to support and manage communication in collaborative product development. To develop suitable organisational reference models for communication infrastructures more research is needed on communication behaviour related to communication infrastructure. The FREE methodology can be used as an initial framework supported by developments in capability maturity models, performance measurement methods and change management.

Development of standards depends on the knowledge available in the industrial and research community. As stressed above (see Section 2.4) a knowledge management approach is needed to build, maintain, and use this knowledge both in the organisational and research community. 


\section{Summary}

In this paper we have argued that more knowledge is needed on the process of collaboration to build methods, tools, and techniques to support management of collaboration. We have introduced the concepts communication behaviour and communication infrastructure to operationalise the concept of collaboration. Research is needed on the relationships between communication behaviour and communication infrastructure to build the necessary knowledge. The FREE methodology resulting from the Esprit 23286 project FREE (Fast Reactive Extended Enterprise) can be used as a starting point for this research. The FREE methodology can be used as a management tool to describe, analyse and improve collaborative behaviour. As such the methodology will help to build knowledge on the process of collaboration as it evolves through changing circumstances and management interventions. A knowledge management approach is necessary to enable building, maintaining, and using this knowledge.

The research envisioned may eventually lead to reference and lifecycle models of communication infrastructures that can support management in selecting and implementing a communication infrastructure to facilitate and manage communication in a specific collaborative project.

\section{Acknowledgements}

We gratefully acknowledge the contributions of all FREE partners in the FREE project to the FREE methodology described in this paper. The FREE partners are: Thomson CSF, Signaal, DASA, Seaview, Adepa, MPC Consultants, Cap Gemini, and University of Twente.

\section{References and Notes}

1 Rossum, W. van (1999) 'Innovation within industries with technological systems characterised by network externalities', Proposal Research Program II, Faculty Technology and Management, University of Twente, Enschede, The Netherlands.

2 Prahalad, C.K. and Hamel, G. (1990) 'The core competence of the corporation', Harvard Business Review, May-June, pp.79-91.

3 Weenink, S.A.J., Wognum, P.M. and Fisscher, O.A.M. (1999) 'Balanced relationships: management of client-supplier relationships in product development', Proceedings of the 1999 $R \& D$ Management Conference on $R \& D$ as a Business, RADMA \& CSIR, New Delhi, pp.343-351.

4 Bremer et al. [5] use the term virtual organisation to denote an organisation that acts as a broker and support organisation for a network of enterprises, mostly small enterprises, to form temporary alliances, called virtual enterprises. Our concept of virtual organisation corresponds to their concept of virtual enterprise, but includes the support processes.

5 Bremer, C.F., Mundim, A.P.F., Michilini, F.V.S., Siqueira, J.E.M. and Ortega, L.M. (1999) 'A Brazilian case of VE coordination', in L.M. Camarinha-Matos and H. Afsarmanesh (Eds.), Infrastructures for Virtual Enterprises, Kluwer Academic Publishers, Boston, pp.377-386.

6 Wildeman, L. and Stoffelen, R. (1996) 'Alliances and networks of the next generation', KPMG report, KPMG Alliances Networks \& Virtual Organisations, Amsterdam, The Netherlands. 
7 Douma, M.U. (1997) 'Strategic alliances: fit or failure', PhD Thesis, University of Twente. Enschede, The Netherlands.

8 Harrigan, K.R. (1985) Strategies for Joint Ventures, Lexington Books, Lexington, MA.

9 Littler, D., Leverick, F. and Bruce, M. (1995) 'Factors affecting the process of collaborative product development: a study of UK manufacturers of information and communications technology products', Journal of Product Innovation Management, Vol. 12, pp.16-32.

10 Pettigrew, A. (1987) 'Context and action in the transformation of the firm', Journal of Management Studies, Vol. 24, No. 4.

11 Mallone, T.W. and Crowston, K. (1994) 'The interdisciplinary study of coordination', ACM Computing Surveys, Vol. 26, No. 1, pp.87-119.

12 Clark, K.B. and Wheelwright, S.C. (1993) Managing New Product and Process Development: Text and Cases, The Free Press, New York.

13 Paashuis, V. (1997) 'The organisation of integrated product development', PhD Thesis, University of Twente, Enschede, The Netherlands.

14 Mintzberg, H. (1979) The Structuration of Organisations: a Synthesis of the Research, Prentice Hall, Inc., Englewood Cliffs.

15 Thompson, J.D. (1967) 'Technology and structure', Organizations in Action, McGraw Hill, New York, pp.51-65.

16 Giddens, A. (1984) The Constitution of Society: an Outline of the Theory of Structuration, University of California Press, Berkley and Los Angeles.

17 Wognum, P.M. and Faber, E.C.C. (1999) 'Duality of integration in collaborative engineering', in P.M. Wognum, K.D. Thoben, K.S. Pawar (Eds.), Proceedings of the 5th International Conference on Concurrent Enterprising, The Hague, The Netherlands, pp.37-44.

18 Kahn, K.B. (1996) 'Interdepartmental integration: a definition with implications for product development performance', Journal of Product Innovation Management, Vol. 13, pp.137-151.

19 Orlikowski, W.J. (1992) 'The duality of technology: rethinking the concept of technology in organisations', Organization Science, Vol. 3, No. 3, pp.398-427.

20 Hornby, A.S. (1974) Oxford Advanced Learner's Dictionary of Current English, Oxford Universtiy Press.

21 Truijens, J., Oosterhaven, A., Maes, R., Jägers, H. and Iersel, F. van (1990) 'Information infrastructure: a management instrument', Informatiemanagement Series, Kluwer Bedrijfswetenschappen, The Netherlands. (in Dutch)

22 Weerd-Nederhof, P.C. de (1998) 'New product development systems, operational effectiveness and strategic flexibility', PhD Thesis, University of Twente, Enschede, The Netherlands.

23 Boer, H. (1991) Organising Innovative Manufacturing Systems, School of Management Studies, University of Twente, Enschede, the Netherlands.

24 Schuring, R.W. (1997) 'Process modelling of dynamics in organisations', PhD Thesis, University of Twente, Enschede, The Netherlands (in Dutch).

25 Wognum, P.M., Weerd-Nederhof, P.C. de and Boer, H. (1997) 'Challenges in organising and managing integrated product development processes. Results of case studies into state-of-the-art in concurrent engineering in industry in the Netherlands', Research Report 97W-001/T\&O-001, University of Twente, Enschede, The Netherlands.

26 Boer, H. and Krabbendam, J.J. (1993) Inleiding Organisatiekunde (Introduction to Organisational Science), University of Twente, The Netherlands.

27 Krabbendam, J.J. (1988) 'New technologies and organisational measures', PhD Thesis, University of Twente, Enschede, The Netherlands (in Dutch).

28 During, W.E. (1986) 'Innovatieproblematiek in kleine industriële bedrijven (Innovation problems in small industrial enterprises)', PhD Thesis, University of Twente, The Netherlands (in Dutch). 
29 Nonaka, I. and Takeuchi, H. (1995) The Knowledge Creating Company, Oxford University Press, New York.

30 Galbraith, J.R. (1974) 'Organisation design: an information processing view', Interfaces, Vol. 4, No. 3, pp.28-36.

31 Moenaert, R.K. and Deschoolmeester, D. (1992) 'Information styles of marketing and R\&D personnel during technological product innovation projects', Journal of $R \& D$ Management, Vol. 22, No. 1, pp.21-39.

32 Jablin, F.M. (1987) 'Formal organization structure', in F.M. Jablin, L.L. Putnam, K.H. Roberts and L.W. Porter (Eds.) Handbook of Organizational Communication. An Interdisciplinary Perspective, SAGE Publications, London, pp.389-419.

33 Faber, E.C.C. (2000) 'Managing the developmental and contextual process of interorganisational collaboration: a cross-cultural perspective', Working Paper, University of Twente, Enschede, The Netherlands.

34 Allen, T.J. (1977) Managing the Flow of Technology, MIT press, Cambridge.

35 Wognum, P.M., Thiry, M. and Weerd-Nederhof, P.C. de (1998) 'Knowledge management in design and product development organisations', Proceedings of the High-Technology Small Firms Conference, Enschede, The Netherlands, pp.601-616.

36 Camarinha-Matos, L.M. and Afsarmanesh, H. (Eds.) (1999) Infrastructures for Virtual Enterprises, Kluwer Academic Publishers, Boston.

37 European Commission (1999) Information Society Technologies, a program of Research, Technology Development \& Demonstration under the 5th Framework of European Research, 1999 Workprogramme.

38 Pawar, K.S. (1997) 'Concurrency for competitiveness: towards the concurrent enterprise in the age of electronic commerce', Proceedings of the 4th International Conference on Concurrent Enterprising (ICE '97), Nottingham, UK.

39 Wognum, P.M., Thoben, K.D. and Pawar, K.S. (1999) 'The concurrent enterprise in operation', Proceedings of the 5th International Conference on Concurrent Enterprising (ICE '99), The Hague, The Netherlands.

40 Crosby, P.B. (1979) Quality is Free: the Art of Making Quality Certain, McGraw-Hill, New York.

41 Hoekstra, A., Hoogeboom, M. and Oei, H. (1998) FREE Improvement Framework, Deliverable 152, ESPRIT project 23286 FREE.

42 Wognum, P.M. and Faber E.C.C. (1998) 'The FREE organisational model', Deliverable No. 122, ESPRIT Project 23286 FREE.

43 Lebrun, J., Gosset, P., Pallot, M., Roux, P., Gandelot, D. and Vannier, M. (1998) FREE Capability Assessment Framework (FREE-CAF). Vol. 1: Overview, Deliverable 132-1, ESPRIT project 23286 FREE.

44 Lebrun, J., Gosset, P., Pallot, M., Roux, P., Gandelot, D. and Vannier, M. (1998) FREE Capability Assessment Framework (FREE-CAF). Vol. 2: Reference Manual, Deliverable 132-2, ESPRIT project 23286 FREE.

45 Lebrun, J., Gosset, P., Pallot, M., Roux, P. and Gandelot, D. (1998) FREE Capability Assessment Framework (FREE-CAF). Vol. 3: Reference Model, Deliverable 132-3, ESPRIT project 23286 FREE.

46 Paulk, M.C., Curtis, B., Chrissis, M.B. and Weber, C.V. (1993) Capability Maturity Model for Software', Version 1.1, Technical Report CMU/SEI-93-TR-24, Software Engineering Institute, Carnegie Mellon University, Pittsburg, USA.

47 Arfman, M., Wagenberg, M. van and Hof, C. (1998) 'Methodology for the FREE performance measurement method', Deliverable 142, ESPRIT project 23286 FREE.

48 Arfman, M., Wagenberg, M. van and Hof, C. (1998) 'FREE performance measurement method guide', Deliverable 143, ESPRIT project 23286 FREE. 
49 Gosset, P., Wagenberg, M. van and Lebrun, J. (1998) FREE SME Adaptation. Vol. 1: Overview and Guidelines to Transpose the FREE Methods to SMEs, Deliverable 202, ESPRIT project 23286 FREE.

50 Gosset, P., Wagenberg, M. van and Lebrun, J. (1998) FREE SME Adaptation. Vol. 2: Tailoring and Implementing the FREE Methods, Deliverable 202-2, ESPRIT project 23286 FREE.

51 The navigation tool can be found at www.kcc.nl/free by selecting the FREE Web presentation.

52 Kerssens-van Drongelen, I.C. (1999) 'Systematic design of R\&D performance measurement systems', PhD Thesis, University of Twente, Enschede, The Netherlands.

53 Bate, R. et al. (1995) 'A systems engineering capability maturity model', Version 1.1, Maturity Model SECMM-95-01, CMU/SEI-95-MM-003, Software Engineering Institute, Carnegie Mellon University, Pittsburg, Pennsylvania.

54 VDI 2221 (1986) Methodik zum Entwickeln und Konstruieren technischer Systemen und Produkte, Verein Deutscher Ingenieure, Düsseldorf.

55 Bennatan, E.M. (1992) Software Project Management: a Practitioner's Approach, McGraw-Hill Book Company, London.

56 PRINCE 2 (1996) CCTA, Norwich, UK. 